\title{
Isabel de Valois como esperanza de paz contra la herejía. Motivos del epitalamio en la oratio cristiana (1560) de Pedro del Frago ${ }^{1}$
}

\author{
Antonio SERRANo CUeTO \\ Universidad de Cádiz \\ antonio.serrano@uca.es
}

Recibido: 26 de octubre de 2011

Aceptado: 21 de noviembre de 2011

\section{RESUMEN}

El artículo presenta un poema latino de Pedro del Frago, concebido como una oratio cristiana, para celebrar la llegada de Isabel de Valois a España (1560). Dicho poema sirve de pretexto para unos largos escolios en los que el autor hace apología del Concilio de Trento y de la pugna católica contra la herejía. Frago ha introducido además en el poema motivos propios del epitalamio, con la posible influencia del humanista Diego de Guevara.

Palabras clave: Pedro del Frago. Isabel de Valois. Poesía neolatina. Concilio de Trento. Epitalamio. Diego de Guevara.

Serrano Cueto, A., «Isabel de Valois como esperanza de paz contra la herejía. Motivos del epitalamio en la oratio cristiana (1560) de Pedro del Frago», Cuad. Fil. Clás. Estud. Lat. 31.2 (2011) 311-331.

Isabel de Valois, a hope for peace against the heresy. Topics of the epithalamium in the Christian oratio (1560) written by Pedro del Frago

\begin{abstract}
This paper offers a Latin poem written by Pedro del Frago, conceived like a Christian oratio, to celebrate Isabel de Valois' arrival in Spain (1560). That poem is as a pretext for doing long annotations in which the author defends the Council of Trent and the Catholic struggle against the heresy. Frago has also introduced some topics of the epithalamium in the poem, perhaps under the influence of the humanist Diego de Guevara.
\end{abstract}

Keywords: Pedro del Frago. Isabel de Valois. Neolatin Poetry. The Council of Trent. Epithalamium. Diego de Guevara.

Serrano Cueto, A., «Isabel de Valois, a hope for peace against the heresy. Topics of the epithalamium in the Christian oratio (1560) written by Pedro del Frago», Cuad. Fil. Clás. Estud. Lat. 31.2 (2011) 311-331.

Sumario 1. Simulación de la autoría. 2. El poema. 3. Los escolios: una revelación contra la herejía. 4. Motivos del epitalamio cortesano. La posible influencia de Diego de Guevara. 4.1. Exhortación a la novia a entrar y buenos auspicios. 4.2. La paz y la Aurea aetas. 4.3. Bonanza del clima y los elementos. 4.4. Deseos de descendencia. 5. Conclusiones. 6. Una propuesta de traducción. 7. Referencias bibliográficas.

${ }^{1}$ Este artículo se inserta en el Proyecto de Investigación FFI2009-10133 de la D.G.I.C.Y.T. 


\section{SIMULACIÓN DE LAAUTORÍA}

La boda de Felipe II e Isabel de Valois en 1560 fue muy celebrada por la pluma de escritores cortesanos de uno y otro lado de los Pirineos. El asunto merecía la mayor atención de las Musas no sólo por tratarse de un enlace regio entre dos poderosas casas reales de la Europa quinientista, sino también porque constituía el broche de la ansiada paz entre España y Francia, dos estados en guerra permanente. Entre quienes se aprestaron al encomio nupcial se cuentan, del lado francés, Jacques du Boys ${ }^{2}$; del lado español, Diego de Guevara ${ }^{3}$ y Hernán Ruiz de Villegas ${ }^{4}$.

Ese mismo año salió de las prensas del taller valenciano de Juan Mey un poema en dísticos elegíacos titulado Ad Isabellam Valesiam, Gallorum regis filiam, Philippo Hispaniarum regi catholico desponsam in Hispaniam ingredientem archangelus eiusdem prouinciae, princeps et defensor bonus. Tales versos, que no superan los setenta, se acompañan de un centenar de páginas de escolios, compuestos para dignificar la religión católica frente al acoso hereje. El conjunto del opúsculo ofrece un título tan prolijo como curioso:

Dialogus, ubi lector quendam forte rogat, qui autoris est amicus, ecquis horum sit carminum scholiorumque scriptor. Cui et ipse amicus in hunc modum respondet: «Nomen ab ipso autore non esse editum, quia eo inconsulto planeque ignaro opusculum hoc emissum sit et typis excusum. Primis tamen sex intermediorum sequentis posteriore pagina epigrammatis uersuum elementis coalescere posse et conflari». Quod eiusdem amici opera factum est, ne elegans plenaque pietatis et eruditionis lucubratio, propositis etiam nonnullis nostrae religionis detrimentis eorumque remediis, delitescere omnino in tenebris, aut sub dium rapta cuiquam uideatur esse suspecta, quod prodierit

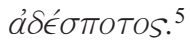

En realidad el término Dialogus no se corresponde ni con la naturaleza del poema ni con la de los comentarios, sino sólo con la del epigrama preliminar, donde en efecto se oculta en acrósticos el nombre del poeta en los seis versos centrales:

\footnotetext{
${ }^{2}$ Es autor de una Comedie et resiovyssance de Paris sus les marriages du Roy Catholique d'Espagne et du Prince de Piedmont aux Princesses de France, mes-dames Elizabet et Marguerite, fille et soeur du Roy très Chrestien Henry II de ce nom y Discours des Triumphes du marriage du Roy Catholique d'Espagne et de madame Elizabeth, fille du Roy tres chrestien Henry ii de ce nom, ambas publicadas en París en 1559. Cf. Amezúa (1949, p.60).

${ }^{3} \mathrm{Su}$ Epithalamium Philippi et Isabelis Hispaniarum regum salió impreso en Alcalá de Henares (J. de Brocar, 1560). Hay edición, traducción y estudio literario en Serrano Cueto (2008).

${ }^{4}$ De pace et nuptiis D. D. Philippi et Isabellae Hispaniae regum libelli duo. Este largo poema en dos libros permaneció manuscrito hasta 1734, fecha en que fue publicado por el Deán Martí.

5 «Diálogo donde el lector por ventura pregunta a alguien, que es amigo del autor, quién ha escrito estos versos y escolios. Le responde el amigo de este modo: «El nombre no ha sido publicado por el propio autor porque este opúsculo ha sido enviado y puesto en letra de molde sin que él fuese consultado ni supiera lo más mínimo. No obstante, con las primeras letras de los seis versos interiores del epigrama de la página siguiente se puede reunir y componer». El mismo amigo es el responsable de que esta elucubración, elegante y llena de piedad y erudición, donde se exponen además algunos menoscabos de nuestra religión y sus remedios, no quedase en absoluto en el olvido, o de que nadie pudiese pensar que era sospechosa porque habia salido publicada bajo anonimato».
} 
Lector: Heus, ubinam autoris nomen? Nam carminis illi Pro meritis magnus esset habendus honos.

Amicus: $\quad$ Forte cupis, qui hoc fecit opus, si nosse: Camoenae (Respice) sex huius prima elementa dabunt.

Lector: A senis conflo id mediis; at promere nomen Gaudeat: autori est laus tribuenda suo.

Amicus: Versibus huic sat erit, quod princeps dixit Iberi, Scripsisse et scholiis explicuisse suis.

Non laudem hinc aliam, non uatis quaerit honorem: Praedicta huic merces, si peragantur, erit.

Como se ve, el nombre es FRAGVS. La epístola nuncupatoria que sigue, fechada en Valencia a 15 de julio de 1560 y dedicada a Melchor Álvarez de Vozmediano, a la sazón obispo de Guadix, está firmada por Petrus Fragus theologus. En ella insiste el autor en la idea ya expresada en el título de que ese amicus autoris se ha tomado la libertad de enviar a la imprenta su obra, que aún debía ser sometida al limae labor:

Communicaui, fateor, ut inter amicos fieri solet, rudia haec commentariola [...] Ex iis quidam cum nec uerbis nec precibus nec conuicio ullo a me tunc posset exprimere, ut properatum hoc scholiorum opusculum emitterem, captata diligentius occasione meas has schedas suffuratus, praefixoque, quod in fronte est, epigrammate, eas ipsas typis excudendas commisit. (Dialogus, ff.Aa 1v.-Aa 2r.)

Pedro del Frago y Garcés (1498-1584) ${ }^{6}$, natural de Uncastillo (Zaragoza), estudió Teología y Artes en París, donde coincidió con altos servidores de la Iglesia, como Ignacio de Loyola y Francisco Javier, y con otros españoles doctos destinados con el tiempo a ocupar diversas diócesis: Álvaro de Moscoso, capellán de Carlos V y obispo de Pamplona; Francisco de Navarra, obispo de Badajoz y de Ciudad Rodrigo y arzobispo de Valencia; y el mencionado Álvarez de Vozmediano ${ }^{7}$. Hombre docto en las lenguas griega, latina y hebrea, fue nombrado obispo de Alés (1562-1566), Alghero (1566-1572) $)^{8}$, Jaca (1572-1577) y Huesca (1577-1584) ${ }^{9}$. Participó en la segunda etapa (1551-1552) del Concilio de Trento como teólogo asesor del susodicho Francisco de Navarra y asistió igualmente a la tercera etapa (1562-1563), pero ya en calidad de obispo de Alés. Intervino en los debates sobre los sacramentos del Orden y del Matrimonio, la existencia del purgatorio y la devoción a las imágenes y los santos.

${ }^{6}$ Las fuentes principales para la biografía de Pedro del Frago proceden de los siglos XVII-XVIII (Aínsa y de Iriarte 1619, pp.482-487; Latassa 1788, pp.402-407), si bien hoy contamos con trabajos recientes que han actualizado y ampliado la información (Moreno 1977, pp.107-154; Morte García 1984, pp.147-176; 1985, pp.57-75; Pedraza García 2011, pp.37-45).

${ }^{7}$ Su propio hermano, Jerónimo del Frago, que fue canónigo de Pamplona, impartía clases en la Sorbona.

${ }^{8}$ De Frago vivió los destinos en estas dos diócesis de Cerdeña como un destierro, según confiesa en carta de 1570 a Antonio Agustín, por entonces obispo de Lérida.

${ }^{9}$ Tareas episcopales de estos últimos años son la reedificación de la iglesia de San Andrés en Uncastillo; el traslado en 1578 de las reliquias de los mártires San Orencio y Santa Paciencia a la iglesia de Loret (Huesca) y las de San Lorenzo desde Roma a la catedral de Huesca. 
Por el entusiasmo con que defendía sus argumentos, recibió entre los conciliares el apodo de «Doctor Porfiado» (Gutiérrez 1951, pp.914-917; Jedin 1975, pp.372, 410, 478).

Además del Dialogus objeto de este trabajo, que publicó cuando residía en Valencia, y otros poemas sueltos, los escritos de Pedro del Frago están consagrados a labores episcopales y teológicas, siempre en consonancia con el espíritu tridentino. Cabe destacar una Oratio ad Patres Concilio Tridentino pronunciada el día de la Ascensión (Venecia, 1551); un Liber constitutionum (Huesca, 1582) para el Seminario Conciliar oscense, que él mismo había fundado en 1580; y un Diario de hechos notables acontecidos en Trento desde 1542 hasta 1560, que quedó manuscrito. Se han conservado también varias epístolas dirigidas a Jerónimo Zurita y Antonio Agustín, estas últimas publicadas en 1937 por F. Miquel Rossel (Carbonell i Manils 1990-91, pp.349-350).

\section{EL POEMA}

Está compuesto por 68 versos, distribuidos en dísticos elegíacos. Se conserva un ejemplar en la Biblioteca Nacional de Madrid (R/28107), que es el que utilizo. La Biblioteca del Escorial guardaba un manuscrito de esta misma obra que al parecer se ha perdido (Alcina Rovira 1995, p. 80; Pedraza García 2011, p.245). He aquí el texto:

Gallorum soboles uirgo clarissima regum, Stemmate quam patrio nec pietate minor,

Ingredere Hispanos, Isabella Valesia, fines Alitibusque bonis haec adeatur humus.

Tu pacem aeternam populis fessoque quietem Quiuisti Gallo conciliare tuo.

Regi Asiae talis quondam si nata fuisset, Omnia cum bellis exagitata forent,

Haec uel Alexandrum, positis uictricibus armis, Flexisset socero pacta puella suo.

Antiochus toto mouet arma Oriente coacta, Vt regno spoliet te, Ptolemaee, tuo.

Oblata, Daniele tibi referente propheta, Placatur nata protinus Antiochus.

Ergo tuis, Isabella, salus sic maxima Gallis, Hispanis eadem grande futura decus,

Sanctorum ut ualde placidam faustissima pacem

Das orbi, cumque hac commoda tanta paris:

Quod felix faustumque siet, desponsa Philippo

Da prolem et sacri pignora grata tori.

Da prolem, ut tribuis pacem, quae Marte subactos

Mox Christi populos cogat inire iugum.

Vt tua cum Carolo soboles terraque marique Auspiciis patriis imperitare queat. 
Da prolem, ut Machometa mali cum stirpe Lutheri,

Vel laetale sui detestans dogma magistri, His ducibus supera iam resipiscat ope.

Sic Carolo natisque tuis comitatus, ut unum Iam pater exactis pascat ouile lupis.

Huc ades, huc, Isabella, Deus (mihi crede) benignus

Tam iusto thalamo pignora certa dabit.

Sic prolem dabis ipsa, patrem nam prole Philippum

Efficies pulchra magnanimaque tuum.

Ingredere Hesperias igitur faustissima terras:

Tu, pax, delitiae tu decus orbis, ades,

Delitiae humani generis superumque cohortis, Gaudia cur tardo nostra morare pede?

Te aduentante silent uenti glaciesque niualis

Liquitur, expulso frigore uernat hyems.

Ver erit aeternum hinc, Zephyroque tepente refertur Seclorum et meritis iam nouus ordo tuis.

Ferrea cum uitiis aetas male sana facesset, Cumque suis aderunt aurea secla bonis,

Non toto tellus misera exercebitur anno,

Rustica uisceribus nec feret arma suis.

Sponte rosas duri diues sine uulnere ferri, Iusto alimenta homini debita fundet humus.

Coelitus ob nostros mores maledicta sinistros, Cum spinis tribulos hactenus ipsa tulit.

Iam coelos terramque nouam dat rector Olympi

Et synodo expulsis gaudia plena malis.

Sic pace aterna nostro uiuetur in orbe,

Praestabit uita hoc pastor et ipse Pius.

En leo iam vitulo, Celtae miscetur Iberus

Atque hoedo pardus, agnus et ipse lupo.

Olim (crede mihi) Sicori famulabitur Ister, Vltroque Pactolus seruiet usque Tago.

Foetiferis Nilus Baetim uenerabitur undis Et famulas Cingae conuehet Indus aquas.

Et Padus et tacito Tigris rapidoque meatu Imperiis suberunt, Turia amoene, tuis.

Quin etiam, Carthago ferox, cogere Sagunti mpensa occasum iam reparare graui.

Cum domino cunctis tandem auxiliaris Ibero Aeternum populis Sequana iura dabunt.

His ergo auspitiis ades huc, Isabella, decusque Perpetuum Hispanis exhibitura, ueni.

El poema presenta una estructura sencilla, con reiteración de varias ideas, en especial el tema de la paz, el deseo de descendencia y la exhortación a Isabel para que entre en el territorio español: 
1. Breve elogio de Isabel (1-2).

2. Exhortación a entrar en España (3-4).

3. Llegada de «Isabel de la paz» (5-18):

a. Beneficios para el orbe y Francia (5-6).

b. Exempla historica (7-14).

c. Beneficios para Francia, España y los cristianos (15-18).

4. Deseos de dicha y descendencia contra la herejía (19-34).

5. Nueva exhortación a entrar (35-38).

6. Bonanza de los elementos (39-42).

7. Aurea aetas del Concilio de Trento (43-56):

$a$. Fertilidad de la tierra (43-52).

b. Paz y convivencia (53-56).

8. Augurios de poder imperial (57-66).

9. Exhortación final a entrar (67-68).

\section{LOS ESCOLIOS: UNA REVELACIÓN CONTRA LA HEREJÍA}

Parte menor de los escolios se destina a explicar las referencias y evocaciones paganas del poema, mas la mayor parte cumple la función de exponer la situación de la Iglesia ante la herejía no sólo en la Europa preconciliar, sino también en el momento presente del poeta, ya iniciado (e interrumpido por segunda vez) el Concilio de Trento.

Al comienzo de la epístola dirigida a Álvarez de Vozmediano hallamos las claves que explican la génesis y naturaleza profética del poema, así como la necesidad de glosarlo. Situado en la más elevada cumbre de los Pirineos, el princeps Hispaniae archangelus ${ }^{10}$ pronuncia una oratio a Isabel de Valois a su paso por Roncesvalles que ha sido revelada a Pedro del Frago, quien habrá de encargarse de interpretar su lenguaje alegórico:

Ex summo Pyraenei montis iugo, qua a Gallis Hispania disterminatur, nescio quo tandem modo ea oratio, quam princeps nostrae prouinciae archangelus ad Isabellam, Henrici Gallorum regis filiam, Philippo Hispaniarum regi catholico eidemque inuictissimo desponsam, cum in Hispaniam esset ingressura, habuit, ad me delata est, iis compositionis numeris [...] Interim uero quanquam dilucida magna ex parte eademque perspicua est, quia tamen allusionibus alegoriisque quibusdam ac prophetico nonnunquam charactere subdifficilis esse uidetur et inuoluta, eam ipsam pro mei imbecillitate ingenii euoluere scholiisque illustrare conatus sum [...] (Dialogus, ff.Aa 1r.-Aa 1v.). ${ }^{11}$

\footnotetext{
${ }^{10} \mathrm{El}$ autor aclara que, aunque todos reciban el nombre de «ángeles», los que están al frente de las naciones son arcángeles (Dialogus, p.4r.), como se infiere de Dn.10.13-21. La aplicación de princeps se inspira sin duda en la expresión Princeps Militiae coelestis, título dado al arcángel San Miguel, protector de Israel. Podría identificarse con el actual Santo Ángel Custodio de España, patrón venerado en algunas localidades de Aragón, tierra de Pedro del Frago.

11 Véase que el autor emplea el cliché orationem habere, que habitualmente significa «pronunciar un discurso», pero es obvio que aquí no se trata de un discurso retórico en prosa, sino una salutación en verso.
} 
¿Por qué un poema que ensalza la llegada de Isabel de Valois a España precisaba de tan extenso comentario? Pedro del Frago quería componer un poema en clave profética que justificara tan dilatada exégesis posterior. El teólogo utiliza el enlace regio como pretexto para invocar la unidad en la ortodoxia, con la esperanza de estimular a los príncipes cristianos para que favorezcan las resoluciones de la jerarquía eclesiástica y acaben con la herejía ${ }^{12}$. Así pues, Isabel de Valois se presenta como esperanza de paz no sólo en el conflicto entre Francia y España ${ }^{13}$, sino también contra cualquier expresión de la herejía. Y aunque el alcance de esta apología es universal, no obstante el poeta alude en la susodicha epístola a Vozmediano a la situación espiritual que se vivía en Valencia a mediados de siglo, especialmente por el problema de los neófitos ${ }^{14}$ :

[...] iterumque, ut ita cum Apostolo dicam, parturiendis Valentini regni neophytis, quos a Christiana religione non minore forsan ecclesiae procerum, quam suo periculo deficere intelligimus, si non acute admodum subtiliterque, at certe pie diligenterque tractantur. (Dialogus, f. Aa1v.)

En la misma epístola el teólogo expresa su deseo de que, bajo los auspicios del rey Felipe ${ }^{15}$, el Concilio de Trento concluya con éxito y restituya el orden en la Iglesia desterrando las herejías que socavan sus fundamentos: represisque Agarenis neophyti ab his profecti (Dialogus, ff.Aa 3v.-Aa 4r.).

Poco antes de iniciar los escolios dístico a dístico, en una breve introducción (Dialogus, pp.4r.-5v.) se expresa el júbilo que siente el arcángel, convencido de que Isabel traerá la paz tanto a España, como a todo el orbe cristiano. Cuando Pedro del Frago se pregunta en el escolio al v. 36: Quod enim orbi maius beneficium, quam pax? (Dialogus, p. 16r.), podría pensarse que se acerca al conocido irenismo de Vives o Erasmo. Sin embargo, como se evidencia en los vv. 21-16 y por extenso en el escolio a los vv. 5254 , esta paz cristiana no parte de la igualdad de los hombres, sino del sometimiento de los disidentes por la autoridad de la Iglesia fortalecida que emane de Trento.

Salvo los vv. 9-10,21-22,27-28,37-38,41,48 y 67-68 ${ }^{16}$, el resto se acompaña de escolios de extensión muy variable. Y si bien el autor va dando cuenta de fuentes lite-

12 El tratado de Passau (1552) y la Paz de Ausburgo (1555), que suponían el reconocimiento del protestantismo en igualdad con la religión católica, habían supuesto un duro revés al sueño de unidad religiosa fraguado durante el imperio carolino e incluso habían hecho tambalearse las aspiraciones de la Iglesia de una reforma general en Trento.

${ }^{13}$ En abril de 1559 los dos reinos habían sellado la paz en el pacto de Cateau-Cambrésis y la joven Isabel era la moneda que ofrecía el monarca francés Enrique II.

${ }^{14}$ En la región de Valencia miles de musulmanes fueron forzados a bautizarse durante las Germanías y, aunque las autoridades eclesiásticas los vigilaban, la vuelta a sus cultos y prácticas fue un hecho. Pedro del Frago deja entrever cierta tolerancia al respecto de las autoridades. Al final de los escolios vuelve a la ciudad del Turia, pero esta vez para denunciar las continuas incursiones de barcos piratas y corsarios berberiscos en la costa valenciana, con los que muchos moriscos tenían trato (Dialogus, p.50r.).

${ }^{15}$ En realidad, Felipe II colaboró decididamente con Pío IV y con los legados y obispos españoles en la reanudación y culminación del concilio.

${ }^{16}$ Normalmente Pedro del Frago deja un dístico sin comentario cuando su relación temática con el anterior o siguiente, sí escoliado, es estrecha. Sin embargo, los vv. 41 y 48, hexámetro y pentámetro respectivamente, carecen de escolio, siendo lo únicos casos en que se desmiembra el dístico. Los vv.67-68 cierran el poema y su coincidencia con el final de la página parece justificar un posible error de impresión que los dejó sin comentario. 
rarias paganas y referencias históricas, la mayor parte de los escolios se dedica a la exégesis religiosa. De ahí que estos sean los más jugosos, pese a ser reiterados en muchos de sus argumentos.

No es mi objetivo ahora analizar estos comentarios, pues el asunto requeriría un trabajo aparte, pero sí me detendré al menos en dos de ellos, los más extensos, por cuanto permitirán al lector hacerse una idea del espíritu tridentino del que está imbuido todo el libro.

El primer pasaje (vv.52-54) se corresponde con un pentámetro y el dístico siguiente y se encuentra en la parte dedicada a la Aurea aetas que habrá de acontecer bajo los auspicios de Trento:

\section{Et Synodo expulsis gaudia plena malis \\ Sic pace aterna nostro uiuetur in orbe, \\ Praestabit uita hoc pastor et ipse Pius.}

Comienza el escolio señalando que el augurio de júbilo de España será posible gracias a Pío IV, papa bajo cuyo mandato culminó el Concilio de Trento. La inclusión en el primer verso de Synodo es la coartada perfecta para extenderse al respecto a lo largo de más de una veintena de páginas (Dialogus, pp. 19r.-32r.). La tesis es clara: dadas las amenazas que se ciernen sobre la Cristiandad, es urgente reavivar las leyes y los usos antiguos de las Sagradas Escrituras y de la Iglesia. A toda controversia ha de responderse con el concurso de los hombres doctos. Sigue una relación de reuniones con toma de acuerdos documentadas en las Escrituras, como la protagonizada por los judíos en Mispá (1Mc.3.46-54), o la de los apóstoles para la elección de Matías como sustituto de Judas Iscariote (Hch.1.15-26). Luego menciona brevemente, entre otros, los concilios celebrados en Antioquía, Ancira, Nicea, Rímini, Cartago, Sinuessa y, cómo no, Trento, que, según lo dicho, en 1560 se encontraba suspendido.

La intención de Pedro del Frago es doble: justificar la tradición de los concilios como medida de afianzamiento de la ortodoxia y sacar a relucir las herejías y cismas históricos. Los concilios han servido y sirven, pues, para evidenciar y corregir las desviaciones del arrianismo, novacianismo, nestorianismo, eutiquianismo, luteranismo..., así como para frenar el avance de los turcos:

Hac, lapsis ad poenitentiam receptis, Nouatus, Paulus Samosatenus, Arius et Eunomius, Macaedonius, Nestorius, Eutyches et Dioscorus Anthymus et Iseodorus, Sergius et Paulus, ac qui uenerabiles sanctorum reliquias et imagines excludunt, qui sacramenta, diuinae gratiae uasa infringunt uniuersique blasphemi atque haeretici quasi Antichristi prophetae et operarii spiritu oris Domini interfecti, obstructo iniquitatis ore, conticescunt [...] Hac iidem ipsi principes ad nefarium Turcarum impetum propulsandum excitantur [...] ut scintillam furialis ac diabolici ignis, prima illa uidelicet, Lutheranae haeresis initia cum habendis in Germania principum comitiis, tum conuocandis proposita fide publica ad liberos doctissimorum hominum conuentus haereticis, opprimeret. (Dialogus, pp. 26v.-27r., 30r.)

En la parte del texto que omito referente a los turcos se apela además al legado del emperador Carlos, cuya imagen responde a los atributos tradicionales de la icono- 
grafía imperial: monarca cristianísimo, vigilante de la fe y Atlas que soporta un nuevo orbe en sus hombros (Checa Cremades 1987, pp.123-124).

El segundo (vv.57-58) se inserta en la sección dedicada a los augurios de expansión del poder del imperio de los Austria, y sirve de explanatio al dístico

\section{Olim (crede mihi) Sicori famulabitur Ister, \\ Vltroque Pactolus seruiet usque Tago.}

La estructura es semejante: comienza con testimonios de las Sagradas Escrituras para fundamentar que todo poder emana de Dios y todo atentado contra su divinidad es castigado, mas no tarda en volver a las herejías y al peligro musulmán, esta vez para recordar que España se vio librada de un sometimiento de ocho siglos gracias a la labor de los Reyes Católicos.

De este escolio, el más extenso del libro (Dialogus, pp.32v.-48r.), merece la pena destacar dos pasajes: el que dedica a la herejía en Valencia y aquel en el que arremete contra otro heterodoxo: Erasmo, la personificación del Anticristo para algunos predicadores $^{17}$.

El asunto de los neófitos en Valencia ya había sido tratado brevemente en la epístola nuncupatoria. Ahora vuelve sobre él para denunciar de nuevo que, pese al bautismo, retornan al culto y prácticas de su antiguo credo musulmán no sólo en los campos y lugares alejados, sino también dentro de los muros de la $\operatorname{ciudad}^{18}$ :

In Hispania (de Valentino id regno potissimum intelligi uolo) impune, nec minus fere licenter, non modo in pagis locisque utcunque desertis, sed intra ipsa Valentinae urbis moenia, quam in Mauritania et Constantinopoli, quod uix sine lacrymis effari possum, sceleratae quaedam Machometici ritus abominationes a baptizatis iam execrabili Christiani nominis blasphemia et summa redemptoris contumelia cunctis conniuentibus peraguntur. (Dialogus, p. 35r.).

La crítica a Erasmo viene al hilo de la defensa que hace Pedro del Frago del vínculo inquebrantable del bautismo, cuya fuerza es capaz de salvar a quienes antes estaban en brazos del demonio. Pero Erasmo había dejado escrito en el prefacio «Al piadoso lector» de su Paráfrasis de San Mateo que convendría preguntar a los bautizados, una vez que se hacían jóvenes, en qué creían y cuál recordaban que era la fe del cristiano. Su tesis era que, cuando llegasen a la pubertad, los jóvenes confirmasen la profesión de fe que habían hecho por ellos quienes los bautizaron. El obispo censura esta opinión del holandés, como ya habían hecho antes los teólogos de la Conferencia de Valladolid (1527) y harán luego en el Concilio de Trento:

Quam ob rem manifestissime constat militare hoc Christianae professionis sacramentum nulla posse ratione dissolui, et importunam illam Erasmicam interrogationem cum impietate ese coniunctissimam. (Dialogus, p.38r.)

\footnotetext{
${ }^{17}$ Para la situación del erasmismo en Valencia en la década de los sesenta, cf. Russell Guillot (2001).

18 Cf. n. 14.
} 


\section{MOTIVOS DEL EPITALAMIO CORTESANO. LA POSIBLE INFLUENCIA DE DIEGO DE GUEVARA}

Con los textos anteriores el lector puede hacerse una idea del propósito que motivó la escritura del poema y los escolios. Ahora bien, el registro poético no podía ser el mismo que el de la prosa exegética. En efecto, el poema responde a otras claves compositivas. La principal de esas claves es que Pedro del Frago ha recurrido al epitalamio tradicional, logrando así una singular combinación de motivos procedentes de la poesía pagana y referencias cristianas y bíblicas ${ }^{19}$.

Si bien tales motivos pueden rastrearse en otros epitalamios cortesanos ${ }^{20}$, es posible que el autor conociese el citado epitalamio de Diego de Guevara (ca. 1537 - ca. 1565), impreso en marzo de ese mismo año en Alcalá de Henares con el aval de un humanista de la talla de Ambrosio de Morales (Serrano Cueto 2006, 2008). En los cuatro meses que median hasta la salida de imprenta del Dialogus (recuérdese que la epístola nuncupatoria al obispo de Guadix lleva fecha de 15 de julio), Pedro del Frago podría haber tenido acceso al opúsculo del madrileño.

El epitalamio de Diego de Guevara es más ambicioso, pues abarca la llegada de Isabel, la boda en Guadalajara y el viaje posterior a Alcalá de Henares, Toledo y Madrid, todo ello con gran exorno poético y mitológico (predicciones, diálogo de divinidades en el Olimpo, intervención de dioses-río), mientras que el poema de Pedro del Frago se limita al momento de la entrada de la novia en suelo hispano. Sin embargo, la comparación de ambos poemas permite abundar en la posibilidad antes mencionada. Las semejanzas se localizan en las exhortaciones a Isabel a entrar España y los buenos auspicios que rodean su llegada, la templanza del clima a su paso por los Pirineos y la evocación de la paz en el marco de la Edad de Oro.

\subsection{EXHORTACIÓN A LA NOVIA A ENTRAR Y BUENOS AUSPICIOS}

La actitud reticente de la novia constituye una constante poética en el epitalamio antiguo (Serrano Cueto 2011). Es frecuente que el poeta (cuando no Himeneo o Venus, ya en el epitalamio narrativo) sea el encargado de tratar de vencer esa resistencia, que se manifiesta en exhortaciones encaminadas a que abandone el hogar paterno y entre en el nuevo hogar y, ya en el tálamo, llamadas a la sumisión al esposo ${ }^{21}$.

A modo de estribillo, Catulo repite en cinco ocasiones la fórmula con la que invita a la novia a salir de la casa: prodeas noua nupta (CATVLL.61.80,95,96,100,110). Con

\footnotetext{
${ }^{19}$ La poesía nupcial del Humanismo no está exenta de esta convivencia de lo pagano y lo cristiano. El epitalamio de Pietro Bonomo en honor de la boda (1494) de Maximiliano I y Bianca Maria Sforza concluye con una invocación a Dios. Lo mismo ocurre al final del epitalamio con el que Jerónimo Ramírez celebra el enlace en 1570 de Felipe II y Ana de Austria (se citará más adelante), donde incluso se alude a un episodio del Génesis.

${ }^{20}$ Como veremos, en Giovanni Pontano, Gabriele Altilio, Pietro Bonomo, Giovanni Gigli, Fausto Andrelini, Jerónimo Ramírez, etc.

${ }^{21}$ Es habitual que, siguiendo los modelos de Ausonio y Claudiano, el encuentro sexual se presente como un proelium nocturnum.
} 
su salida se inicia la deductio, donde se ha querido ver un auténtico rito de separación e iniciación en la vida adulta (Laigneau 1999, p.211).

La utilización política del matrimonio para establecer alianzas dinásticas en la Italia de los siglos XV-XVI provocó un cambio sustancial en la deductio, pues se pasó de un recorrido breve, normalmente de ámbito local, en las bodas de Grecia y Roma, a un viaje entre regiones, estados e incluso entre reinos distantes. Esto conlleva la adaptación a esta realidad de la antigua fórmula con la que se animaba a la novia a salir de la casa paterna y cruzar el umbral de la nueva casa.

Giovanni Pontano (1422-1503), seguidor de Catulo y uno de los poetas que inician el cultivo del epitalamio en verso en la segunda mitad del Quattrocento ${ }^{22}$, compuso un Epithalamium Leonorae Aragoniae en 1473 para festejar el viaje de Eleonora de Aragón, hija del rey Ferrante I de Nápoles, a Ferrara, donde habría de contraer matrimonio con Ercole I d'Este, duque de Ferrara. En dicho poema, de tono muy distinto al de los epitalamios familiares del De amore coniugale ${ }^{23}$, Pontano exhorta a la joven novia a entrar en el tálamo y buscar descendencia ${ }^{24}$ :

\section{I, uirgo felix, i maritos}

Prole noua thalamos replere (vv. 95-96)

Lo mismo hace Gabriele Altilio ( $c a$.1436-1501), poeta de Salerno amigo de Pontano, en el largo epitalamio que compuso para la boda de Gian Galeazzo Sforza, VI duque de Milán, e Isabel de Aragón, celebrada en Milán en febrero de 1489. Llevaba por título Carmen in nuptiis illustrissimi Galeacii M. Sfortiae, ducis Mediolanensis, et Isabellae Aragoniae ${ }^{25}$ :

Tu quoque Sfortiacos, uirgo, accesura penates, cognatas i laeta domos, gens inclyta mater (vv.146-147)

El humanista español Jerónimo Ramírez (s. XVI) empleará el mismo recurso al exhortar a Ana de Austria, cuarta esposa de Felipe II, en el Epithalamion de nuptiis Philippi II, Hispaniarum regis catholici, et dominae Annae, Maximiliani Romanorum imperatoris filiae que publicó en Madrid en 1572 (Serrano Cueto 2009b). El uso del imperativo es idéntico al que hemos visto en Pontano y Altilio:

I, foelix uirgo, magno socianda marito,

Regia progenies et fessis anchora rebus;

\footnotetext{
22 Desde mucho antes, en el primer tercio del siglo, se venían componiendo discursos nupciales (orationes, aunque también denominados bajo el genérico epithalamia) en el círculo de Guarino de Verona. Y la segunda mitad del siglo estará jalonada en Italia por estos discursos (Guiniforte Barzizza, Francesco Patrizi, Francesco Bertini, Francesco Filelfo, Angelo Constanzi, Pandolfo Collenuccio, Giovanni Brancati...). Cf. Nichilo (1995).

${ }^{23}$ El erotismo de los poemas nupciales dedicados a su propia boda con Adriana Sassone y a las de sus hijas Aurelia y Eugenia, así como a la de su amigo Giovanni Brancati, está ausente en este epitalamio cortesano.

${ }^{24} \mathrm{El}$ poema, de un centenar de versos distribuidos en estrofas alcaicas, fue editado por Soldati (1902, pp.412-415).

${ }^{25}$ Cito por la edición de Lamattina (1978).
} 


\section{I, digna Hesperiae sceptrum gestare tremendum}

Et digna omniparae regnis succedere terrae. (vv.134-137)

Al cantar la boda entre la princesa Juana de Austria y el príncipe Juan de Portugal en 1552, el poeta lusitano Jerónimo Cardoso (ca. 1508 - ca. 1569) escribió un Epithalamion serenissimae D. Ioannae Caesaris Caroli quinti filiae ${ }^{26}$ que recoge la llegada de Juana a Lisboa. Se sitúa, pues, en el suelo del hogar conyugal. El poeta pone en boca del rey Juan III la invitación a Juana a entrar en su reino, con términos semejantes a los empleados por Pedro del Frago:

Ingredere, o coniux, inquit, charissima nati

Atque eadem nostrae de stirpe creata sororis,

Ingredere, ofelix, regnis potiere beatis, (vv.64-66)

Pero volvamos a Isabel de Valois.

La novia partió de la corte de Francia y atravesó los Pirineos por Roncesvalles a primeros de enero de 1560, donde la esperaba un séquito numeroso capitaneado por Iñigo López de Mendoza, IV duque del Infantado, en cuyo palacio de Guadalajara habría de celebrarse la boda, y Francisco de Mendoza y Bobadilla, obispo de Burgos, que sería el encargado de oficiar la misa ${ }^{27}$. Allí, en la frontera pirenaica, el ángel exhorta a la joven a entrar en territorio español en tres ocasiones: al principio, hacia la mitad del poema y en el verso final. Utiliza para ello formas de los verbos ingredi (dos veces), adesse (tres veces) y uenire (una vez). Los tres verbos aparecen en Diego de Guevara y, en el caso de los dos primeros, con idéntica forma:

\section{GUEvara Hesperiam ingredere populosque urbesque tuorum (v.21) Ergo adsis, regina, auibus iam laeta secundis (v.18) \\ FRAGO Ingredere Hispanos, Isabella Valesia, fines (v.3) Ingredere Hesperias igitur faustissima terras (v.35) Huc ades, huc Isabella, Deus (crede mihi) benignus (v.31) His ergo auspitiis ades huc, Isabella, (v.67) Alitibusque bonis haec adeatur humus. (v.4) ${ }^{28}$}

Nótese que en v. 67 la coincidencia no se limita al verbo adessse ${ }^{29}$, sino que se amplía al adverbio ergo y a un sustantivo (auspitiis) que en este contexto es sinónimo del auibus del verso 18 de Diego de Guevara.

\footnotetext{
${ }^{26}$ Utilizo la edición de Lisboa, Juan Barreiro, 1564.

${ }^{27}$ El itinerario que siguió desde la frontera hispano-gala hasta Guadalajara, ciudad en la que entró el 28 de enero, fue recogido por cronistas como Ginés de Sepúlveda. No hay unanimidad en la fecha exacta de la boda, aunque suele fecharse el 2 de febrero.

${ }^{28}$ En el escolio a este verso (Dialogus, p. 6r.) Pedro del Frago parece excusarse por aludir a la gentilium superstitio de los augures, pero añade a continuación que es una forma poética de la que se sirve el arcángel para desear que la llegada de Isabel sea muy dichosa.

${ }^{29}$ La forma ades imita el discutido adest/ades de CATVLL 61.77.
} 
El imperativo de uenire empleado por Pedro del Frago no tiene equivalencia tal cual en el epitalamio del poeta madrileño, pero en este sí aparece el verbo uenire en cuatro ocasiones al anunciarse la llegada de Isabel a Alcalá de Henares:

GUEVARA Expectat, sed uenit: io clamemus ouantes,

Venit, io, nostram Isabel iam uenit in urbem,

Venit, io clamemus, io clamemus ouantes. (vv.68-70)

Frago Perpetuum Hispanis exhibitura, ueni. (v.68)

Siguiendo la estela del epitalamio catuliano (CATVLL. 61.90: sed moraris, abit dies), el aragonés recurre incluso al tópico citado de la reticencia de la novia, que demora su salida y necesita por ello que la apremien:

Gaudia cur tardo nostra morare pede? (v.38)

\subsection{LA PAZ Y LA AUREA AETAS}

Desde la laus sponsae inicial (Gallorum soboles uirgo clarissima regum, / Stemmate quam patrio nec pietate minor, vv.1-2), todo el poema se consagra a la imagen de «Isabel de la Paz», como muy pronto fue titulada la joven. De hecho, al pasar por los distintos pueblos y ciudades salían a recibirla con letrillas y vítores. Una de ellas decía: «Del cielo a Francia vinieron, / del cielo a España han venido, / pues la Paz nos han traído» (Amezúa 1949, p.127). Se prescinde, pues, de motivos habituales en el encomio de la novia como la belleza o la educación ${ }^{30}$. Ello no debe extrañar, pues era un locus communis casi obligado no sólo en los escritos laudatorios de la futura reina ${ }^{31}$, sino también en los mensajes de la arquitectura efímera levantada para el evento en ciudades como Toledo ${ }^{32}$. De ahí que Diego de Guevara incluya en su epitalamio una extensa lamentación de la diosa Paz (vv.87-140) que sigue de cerca el modelo de la Querela Pacis de Erasmo. Según la predicción de Júpiter en respuesta a la diosa, de Catalina de Médicis nacería una hija que pondría fin a la guerra entre Francia y España: Isabel. En Guevara este largo pasaje está estrechamente ligado al tema de la $\mathrm{Au}$ rea aetas (Serrano Cueto 2009a).

El asunto no atañía sólo a esta reina, ya que cualquier gobernante o consorte era susceptible de ser adornado con las virtudes que la retórica epidíctica establecía en el encomio imperial (valentía, justicia, templanza y sabiduría [Men.RH.373.8-9]). Por

\footnotetext{
${ }^{30}$ El epitalamio narrativo-épico, representado en la Antigüedad por las composiciones de Estacio y Claudiano, concede un lugar importante a la laus coniugum, que, en el caso del varón, no es más que la adaptación del encomio del príncipe.

${ }^{31}$ En el epitalamio citado de Hernán Ruiz de Villegas la paz también es un tema constante.

${ }^{32}$ De ello da testimonio Álvar Gómez de Castro en el Recibimiento que la imperial ciudad de Toledo hizo a la Magestad de la Reyna nuestra señora doña Ysabel, hija del Rey Henrrico II de Francia, quando nueuamente entró en ella a celebrar las fiestas de sus felicíssimas bodas con el Rey don Philippe nuestro señor II de este nombre (Toledo, J. de Ayala, 1561).
} 
otra parte, de esas virtudes emanaba, como reverso de la cara guerrera, el carácter pacificador. La imagen del rex pacificus forma parte de la iconografía de Carlos V y de su hijo, el rey Felipe (Checa Cremades 1987, pp.140-148).

Muchos epitalamios neolatinos de los siglos XV-XVI incluyen el tema de la paz, ya que éste era uno de los fines que se perseguía con los matrimonios pactados entre casas principales ${ }^{33}$. Acabamos de ver el caso Diego de Guevara, mas lejos de nuestras fronteras cabe citar, por ejemplo, al poeta italiano Fausto Andrelini (ca. 1462-1518). Compuso un epitalamio hacia 1506 para celebrar la boda de Claudia, hija del rey francés Luis XII, y el duque Francisco de Valois, futuro rey de Francia. En él hace un elogio del pacificum sceptrum del rey que ocupa veintiocho versos, casi la mitad del poema. El pasaje, que va seguido de una evocación de la Aurea aetas, recuerda el himno a la paz de Tibulo (1.10). He aquí una muestra, según la edición de Tournoy-Thoen (1977, pp.73-75):

Tu commune libens uotum, Ludouice, probasti, Vnde fit in Francis pax sit ut alma plagis.

Candida pomosis semper pax uernat in ortis, Oreque florigeras nutrit h[a]yante comas.

Pax arat ingenti parituram fenore terram, Et socio letam cum boue pascit ouem. (vv. 25-30)

Como se ha dicho, todo el poema de Pedro del Frago es un encomio de «Isabel de la Paz» y a este fin se consagran distintos recursos. Así los dos exempla: el del rey persa Darío, cuya hipotética hija podría haber facilitado la paz con Alejandro Magno (vv. 7-10), y el de los reyes Antíoco II Teós y Ptolomeo II Filadelfo, que firmaron la paz gracias al matrimonio de Berenice, hija de Ptolomeo, con Antíoco (vv. 11-14).

En los vv. 15-18 se produce el paso de la pacificación de los reinos de Francia y España a la de todos los cristianos. Con ello Pedro del Frago lleva al lector al terreno que le interesa: la guerra contra la herejía. Porque ya se ha dicho: la paz que predica el obispo es en realidad el fruto de las guerras de sometimiento de los infieles. Así lo expresa de modo explícito en los vv.21-22:

\section{Da prolem, ut tribuis pacem, quae Marte subactos Mox Christi populos cogat inire iugum.}

Como en los epitalamios citados de Diego de Guevara y Fausto Andrelini, la paz forma parte de la Aurea aetas, tema que venía asociándose a los gobernantes desde tiempos del emperador Augusto (Zanker 2005, pp.220), había sido empleado por artistas y escritores de la época de los Reyes Católicos (Gómez Moreno - Jiménez Calvente 2002) y será recurso también en la iconografía de los reinados de Carlos V y Felipe II. De hecho, formará parte de la propaganda preparada para el recibimiento de

\footnotetext{
${ }^{33}$ Incluyen el tema de la paz en sus epitalamios, entre otros, el poeta elegíaco Clemens Janicki, los citados Giovanni Pontano y Jerónimo Ramírez y Giovanni Gigli.
} 
Ana de Austria en Madrid en 1570, como vemos en el Real Apparato y sumptuoso recebimiento con que Madrid (como casa y morada de su M.) rescibió a la Serenissima reyna D. Ana de Austria, publicado en 1572 en Madrid por Juan López de Hoyos (Jiménez Garnica y otros 1999, p. 56) ${ }^{34}$.

En efecto, en tiempos de los Reyes Católicos lo hallamos en la pluma de Nebrija. En su Epithalamium in nuptiis clarissimorum Lusitaniae principum Alphonsi ac Helisabes (Salamanca, 1491), el sevillano incorporó una referencia a la Edad de Oro a partir del célebre pasaje profético virgiliano (Ecl.4.5-7):

Et sua ductorum se quisque in regna recepit

Et qui disperiit redditus ordo sibi est.

Tum rediit uirgo. Redierunt tempora pacis,

Quasque colit partes pacis alumna quies. (vv.35-38)

La Edad de Oro que propugna Pedro del Frago (vv.43-56) no resultará solamente de la pacificación política de los reinos, sino que en ella ejercerá un papel primordial el Concilio de Trento, bajo los auspicios del papa Pío IV, como se explica profusamente en el más extenso de los escolios. No obstante, hay motivos tradicionales, como la generosidad de la tierra, que dará frutos sin que la trabajen los humanos (v.48)-con claras reminiscencias de Ovidio (Met.1.101-106)-, y la paz (v.53). Tanto Diego de Guevara como Pedro del Frago destacan la convivencia del pastor con el lobo, pero, mientras que el primero está recurriendo a una imagen tradicional de la Aurea aetas, el teólogo aragonés está evocando un pasaje de las Sagradas Escrituras ${ }^{35}$ :

GUEVARA Auspiciis, regina, tuis Saturnia saecla
Iam redeunt, terras Themidos iam nata reuisit.
$[\ldots]$
Pax uenit: ecce auido securus uomere taurus
Vertir foeda situ squalentiaque arua colonis
Abductis, niueas spectat de rupe capellas
Pastor, et arguta modulatur carmina canna,
Nec pauidus saeuum metuit rabida ora luporum. (vv. 277-284)
Seclorum et meritis iam nouus ordo tuis.
Ferrea cum uitiis aetas malesana facesset,
Cumque suis aderunt aurea secla bonis,
Non toto tellus misera exercebitur anno,
Rustica uisceribus nec feret arma suis.
Sponte rosas duri diues sine unlnere ferri,
Iusto alimenta homini debita fundet humus.
$[\ldots]$

\footnotetext{
${ }^{34}$ El programa de propaganda política y religiosa en torno a Isabel de Valois y Ana de Austria continuó incluso en sus exequias, como han puesto de relieve Espigares Pinilla (2008) y Pozuelo Calero (2004).

${ }^{35}$ Is.11.6-7: «Serán vecinos el lobo y el cordero y el leopardo se echará con el cabrito, el novillo y el cachorro pacerán juntos...»
} 
Sic pace aterna nostro uiuetur in orbe,

Praestabit uita hoc pastor et ipse Pius.

En leo iam uitulo, Celtae miscetur Iberus,

Atque hoedo pardus, agnus et ipse lupo. (vv.42-48, 53-56)

\subsection{BONANZA DEL CLIMA Y LOS ELEMENTOS}

En el epitalamio de Estacio (Silv. 1.2.155-156) y en los uersus Fescennini de Claudiano (12.18-45) en honor del príncipe Honorio se menciona la bonanza del clima el día de la boda. La ausencia de estaciones en el primero y la primavera sobrevenida en el segundo responden a un artificio retórico habitual ${ }^{36}$.

El paso de Isabel por Roncesvalles y luego por Navarra estuvo acompañado de ventiscas, tormentas de nieve y fuertes vientos. De ahí que la deseada templanza del clima se ubique justo en el momento en el que la joven atraviesa los Pirineos. En esto también coinciden Diego de Guevara y Pedro del Frago. En el epitalamio del madrileño se abre una ruta entre las montañas y el hielo se deshace con el soplo primaveral de Céfiro. En el poema de Pedro del Frago, los vientos se calman, el hielo se derrite y sobreviene una primavera eterna con el soplo del mismo Céfiro, en un pasaje deudor de Ovidio (Met.1.107-108: Ver erat aeternum, placidique tepentibus auris / mulcebant Zephyri natos sine semine flores):

Guevara En tibi laeta iugis uenienti cana Pyrenne

Pandit iter scopulosque feros praeruptaque saxa

Emollisse cupit rigidoque obstantia gelu

Flumina Sythoniasque niues hyemisque fragorem

Fregisse et uerno Zephyri soluisse tepore. (vv.23-27)

FRAGO Te aduentante silent uenti glaciesque niualis

Liquitur, expulso frigore uernat hyems.

Ver erit aeternum hinc, Zephyroque tepente refertur, (vv.39-41)

En el escolio a estos versos el aragonés explica el sentido simbólico de esta templanza del rigor invernal. El clima duro se torna plácido como señal de la llegada de un tiempo mejor, pleno de dicha, en consonancia con la predicción de la Edad de Oro: signa sunt perspicua redditi felicioris aeui (Dialogus, p. 17r.). Ahora bien -el obispo vuelve a la carga-, ha de entenderse que el rigor del invierno y la dureza del clima son el castigo por los pecados del hombre, entre ellos el de herejía:

[...] negari non possit, hyemis aestatisque molestiarum et asperitatem et ipsam coeli intemperiem ex peccato homini prouenire [...] (Dialogus, p.16v.)

\footnotetext{
${ }^{36}$ Menandro el Rétor (410.18-19) aconsejaba brevemente que se hablase de la estación. Por otra parte, el anónimo Epithalamium Patricii (PLM 5.118 Baehrens) comienza precisamente con versos dedicados a la primavera.
} 


\subsection{DESEOS DE DESCENDENCIA}

Los epitalamios solían cerrarse con la llamada adlocutio sponsalis, o expresión por parte del poeta de deseos de prosperidad, amor mutuo y descendencia para la pareja. La retórica formalizó estos votos en una plegaria en la que se pedía a los dioses vida dichosa e hijos (Men.RH.411.19-22). La descendencia, pues, era parte importante de esta adlocutio, y a menudo se añadía la predicción de que los hijos se parecerían a los padres en físico y virtudes.

Hasta siete veces alude Pedro del Frago a la descendencia de Isabel y Felipe, repitiendo incluso expresiones, como da prolem (vv.20, 21, 25, con dabis en el v.33), Vt tua cum Carolo soboles (v.23), natisque tuis (v.29), pignora certa (v.32). El teólogo justifica las repeticiones argumentando que no son fruto ni del deseo ni de una actitud apremiante por parte del arcángel, sino un signo de la certeza y alegría con la que aguarda la descendencia real ${ }^{37}$.

Ahora bien, para que no puedan malinterpretarse sus palabras, en el escolio correspondiente al v.23 deja bien claro que ese Carolus es el infante Carlos, legítimo heredero de la corona ${ }^{38}$. En el v.29 (Sic Carolo natisque tuis comitatus, ut unum) insiste en que los hijos de Isabel vienen a acompañar a Carlos en la misión de garantizar la continuidad de la unidad religiosa que, bajo el imperio, había soñado Carlos V.

El pasaje (vv.19-34) comienza con el deseo de felicidad conyugal, uno de cuyos signos habrá de ser la expansión del poder imperial a través de los herederos. En el escolio de los vv.19-20 deja su impronta como teólogo, al afirmar que los hijos son uno de los tres bienes que concede el matrimonio (unum est enim ex tribus matrimonii bonis, fructusque dulcissimus (Dialogus, p.10v.). Y en el v.20 coloca la procreación bajo el amparo del sacramento: Da prolem et sacri pignora grata tori. He aquí otra constante de los epitalamios neolatinos: la legitimación del amor y el sexo en el seno del matrimonio, idea que ya estaba en Catulo (61.44-45,139-141) y Estacio (Silv.1.2.2829 ) y es uno de los argumentos del encomio del matrimonio en la tesis habitual de los progymnasmata: «si es conveniente casarse» (APHTH.,Prog.13).

Pero, como ya advertí, pronto irrumpe el verdadero propósito del teólogo, pues la prole futura de Isabel se presenta como el ariete contra los seguidores de Arrio, Nestorio, Novato, Eutique, Macedonio, Mahoma, Lutero y cuantos herejes (lupi) asuelan la cristiandad (vv.25-26, 29-30) ${ }^{39}$.

Diego de Guevara despacha el asunto de la descendencia en seis versos (vv.266$269,274-275)$ y no hay en su epitalamio exhortaciones directas a la novia. Eso sí, co-

\footnotetext{
${ }^{37}$ Aduertendum tamen hic eiusmodi uoces 'da prolem' et cetera, ita hic ab Angelo repetitas non tam esse flagitantis aut optantis, quam exultantis iam de sobolis futurae certitudine (Dialogus, pp.11r. y 15r.).

${ }^{38}$ El 22 de febrero de 1560 Felipe II hizo que las Cortes de Castilla, reunidas en Toledo, nombraran a su hijo Carlos heredero del trono. Aún no había cumplido 15 años.

${ }^{39}$ La extensión de los escolios dedicados a los vv. 20-30 (Dialogus, pp.10v.-14v.) dan buena cuenta de la importancia que Pedro del Frago concede a este asunto. Los hijos de los monarcas, enviados a diversas partes de la tierra, actuarían a favor de la unidad de la Iglesia. Con los arrepentidos cabe utilizar la clemencia, pues vuelven al redil, pero con los contumaces, la única solución es su destrucción, porque ninguna salvación hay fuera de la Iglesia (nulla extra ecclesiam salus), doctrina que es fundamento de la bula Unam sanctam de Bonifacio VIII (1302).
} 
incide con Pedro del Frago en una idea que, evidentemente, formaba parte de la propaganda imperial: con la prole de los esposos (multiplex, según deseo del madrileño) crecería la gloria de España y del imperio:

Guevara Multiplici Hesperiae consugat gloria partu (v.269)

FRAGO Vt tua cum Carolo soboles, terraque marique

Auspiciis patriis imperitare queat. (vv.23-24)

\section{CONCLUSIONES}

Con este poema Pedro del Frago se suma a la larga lista de poetas cortesanos que celebran el matrimonio político en la Europa quinientista, pero, a diferencia de Pontano, Altilio, Bonomo, Andrelini, Dantisco, Cardoso y otros humanistas, no lo hace recurriendo formalmente a un epitalamio, sino a una suerte de salutación cristiana que, con singular retorcimiento poético, atribuye a una revelación divina por voz interpuesta del ángel. Sin embargo, buena parte del poema ha de verse en la misma clave que los epitalamios, pues difícilmente el obispo de Huesca podía sustraerse a una forma de composición que mantenía viva su tradición desde la Antigüedad y que hallaba en la sociedad de los siglos XV-XVI un excelente caldo de cultivo.

Por otra parte, no debemos pasar por alto que, con todo, el poema es un mero pretexto para organizar un gran alegato en defensa del Concilio de Trento y su pertinencia en aquellos años de convulsión espiritual. Con estos versos y su larga explanatio se proponía no sólo recabar mayor apoyo del rey Felipe para la reanudación del concilio, sino también denunciar lo que entendía como flagrante permisividad de las autoridades ante el avance de la disidencia en el seno de la Iglesia europea.

\section{UNA PROPUESTA DE TRADUCCIÓN}

Doncella, hija ilustre de los reyes galos, que no desmereces en piedad del linaje paterno,

Isabel de Valois, entra en la frontera hispana y buenos auspicios favorezcan esta tierra.

Has sido capaz de llevar paz eterna a los pueblos y sosiego al galo cansado.

Si una hija tal hubiese tenido antaño el rey de $\mathrm{Asia}^{40}$, cuando las guerras lo sacudían todo,

esta joven incluso a Alejandro, depuestas las armas vencedoras, hubiese doblegado, luego de pactar con su suegro ${ }^{41}$.

Antíoco promueve las armas reunidas en todo Oriente para apoderarse de tu reino, Ptolomeo.

\footnotetext{
${ }^{40}$ Alusión a Darío, rey de los persas.

${ }^{41}$ Alejandro Magno, cuyo padre, el rey Filipo de Macedonia, hubiese sido el suegro de esta hipotética joven.
} 
Según la profecía que pronuncia para ti Daniel, el ofrecimiento de tu hija aplaca de inmediato a Antíoco ${ }^{42}$.

Por ello, Isabel, serás la máxima salvación de tus galos y también la honra de los hispanos,

igual que concedes muy propicia una paz tan serena al orbe cristiano, con la que lo colmas de beneficios.

Sea para felicidad y prosperidad: como esposa de Felipe dale hijos y vástagos dulces del lecho sagrado.

Dale hijos, como otorgas la paz, para que sometan en la guerra a los pueblos y luego los obliguen a llevar el yugo de Cristo;

para que tu descendencia pueda gobernar junto con Carlos ${ }^{43}$ por tierra y mar con los auspicios paternos.

Dale hijos, para que Mahoma y la estirpe del malvado Lutero se vean abismados en las aguas estigias,

o, despreciando el dogma mortal de su maestro, con estos príncipes y la ayuda del cielo ya se corrijan.

La compañía de Carlos y tus hijos será tal, que el padre apacentará un único rebaño, muertos los lobos ${ }^{44}$.

Llega aquí, Isabel, aquí; Dios bondadoso (créeme) dará descendencia segura a tan justo tálamo.

Así tú misma darás hijos, pues harás padre a tu Felipe con hijos hermosos y magnánimos.

Así que entra muy venturosa en las tierras de España, llega tú, paz, tú, dulzura y gloria del mundo,

dulzura para la raza humana y para el cielo. ¿Por qué demoras nuestro júbilo con paso tardo?

A tu llegada amainan los vientos y la nieve helada se derrite y, apartado el frío, el invierno se torna primavera.

De aquí habrá eterna primavera y con el céfiro templado retorna ${ }^{45}$ ya un nuevo orden de los siglos merced a tus actos.

Cuando se aleje la malsana Edad de Hierro con sus vicios y llegue la Edad de Oro con sus bienes,

no se trabajará la tierra yerma en todo un año, ni soportará en sus entrañas los aperos de labranza.

Fecunda sin la herida del hierro cruel, espontáneamente la tierra ${ }^{46}$ esparcirá rosas y los alimentos debidos al hombre justo.

Maldita por el cielo a causa de nuestras funestas costumbres, abrojos con espinas produjo ella hasta hoy ${ }^{47}$.

\footnotetext{
${ }^{42}$ Antíoco II Teós, rey seléucida, trabó guerra durísima con Ptolomeo Filadelfo II, rey de Alejandría. Éste puso fin a la guerra entregando la mano de su hija, Berenice, a Antíoco. La profecía se halla en Dn.11. 6-11.

${ }^{43}$ El infante Carlos, heredero de la corona en ese momento.

${ }^{44}$ De nuevo la idea de la unidad religiosa que pretendió el abuelo Carlos V, ya expresada en bula papal mencionada en la nota 39. El verso alude al pasaje bíblico de Jn.10.16.

45 Véase lo dicho en el epígrafe 4.3.

${ }^{46}$ Cf. Ov.Met.1.101-102.

${ }^{47}$ Alusión a la esterilidad de la tierra como castigo por el pecado original. Frago parafrasea los versículos de Gn.3.17-18: Maledicta terra in opere tuo, in laboribus comedes ex ea cunctis diebus uitae tuae: spinas et tribulos germinabit tibi.
} 
Ya el señor del Olimpo da cielos y tierra nueva y alegría absoluta, una vez expulsados los males en un concilio.

Así se vivirá con paz eterna en nuestro mundo, cumplirá esta tarea en vida justamente el pastor $\mathrm{Pí}^{48}$.

He aquí que convivirán el léon con el novillo, el ibero con el celta, el leopardo con el cabrito y hasta el cordero con el lobo ${ }^{49}$.

Día vendrá (créeme) en que el Istro sea sirviente del Sicoris ${ }^{50}$ y además el Pactolo servirá siempre al Tajo ${ }^{51}$.

El Nilo de fétidas aguas venerará al Betis y el Indo transportará sus aguas al servicio del Cinga ${ }^{52}$.

Y el Po y el Tigris de callado y rápido caudal se someterán a tu imperio, ameno Turia.

Es más, fiera Cartago, te verás obligada a reparar ahora la caída de Sagunto con considerable sacrificio ${ }^{53}$.

El señor Ebro y su auxiliar el Sequana impartirán a todos los pueblos justicia eternamente ${ }^{54}$.

Así pues, con estos auspicios llega aquí, Isabel, $\mathrm{y}$, para mostrar tu gloria perpetua a los hispanos, ven.

\section{REFERENCIAS BIBLIOGRÁFICAS}

AÍNSA Y DE IRIARTE, F. D. (1619), Fundación, excelencias, grandezas y cosas memorables de la antiquísima ciudad de Huesca, Huesca, Pedro Cabarte.

Alcina Rovira, J. F. (1995), Repertorio de la poesía latina del Renacimiento en España, Salamanca, Ediciones Universidad.

AmezúA, A. de (1949), Isabel de Valois. Reina de España (1546-1568), I, Madrid.

CARbonell i Manils, J. (1990-91), «Quatre cartes desconegudes de l'arquebisbe de Tarragona», Faventia 12-1, 337-352.

Checa Cremades, F. (1987), Carlos Vy la imagen del héroe en el Renacimiento, Madrid, Taurus.

Espigares Pinilla, A. (2008), «Función política de las letras y jeroglíficos en las exequias del príncipe Don Carlos y de Isabel de Valois en Madrid (1568)», en CHAPARRO, C. - JUlio García, J. - Roso, J. - Ureña, J. (eds.), Paisajes Emblemáticos: la construcción de la imagen simbólica en Europa y América, Cáceres, Junta de Extremadura, pp. 361-374.

Gómez Moreno, A. - JimÉnez CAlvente, T. (2002), «Entre edenismo y aemulario clásica: el mito de la Edad de Oro en la España de los Reyes Católicos», Silva 1, 113-140.

\footnotetext{
48 Pío IV (1499-1565), pontífice romano entre 1560 y 1565. Convocó la tercera y última fase del Concilio de Trento.

49 Alusión a Is. 11.6-7: Habitabit lupus cum agno et pardus cum haedo accubabit; vitulus et leo et ouis simul morabuntur, et puer paruulus minabit eos. Vitulus et ursus pascentur.

${ }^{50}$ Los ríos Danubio y Segre, respectivamente.

${ }^{51}$ Según la leyenda, tanto el Pactolo (río de Lidia, en la actual Turquía), como el Tajo arrastraban granos de oro entre sus arenas.

${ }^{52}$ Afluente del Segre (hoy Cinca).

${ }^{53}$ Cartago está, por sinécdoque, por toda África, según nos aclara en el escolio (Dialogus, p. 49v.).

${ }^{54}$ El Sequana (Sena) y el Ebro simbolizan la unión de los reinos de Francia y España.
} 
Gutiérrez, C. (1951), Españoles en Trento, Valladolid, C.S.I.C.

Jedin, H. (1975), Historia del Concilio de Trento, III, Pamplona.

JimÉnEZ GARniCA, A. Mª y otros (1999), Fiestas nupciales en el Madrid de Felipe II, Madrid, Comunidad de Madrid.

Laigneau, S. (1999), La femme et l'amour chez Catulle et les Élegiaques augustéens, Bruselas, Latomus.

Lamattina, G. (1978), Gabriele Altilio. Poesie, Salerno, Arti Grafiche dell'Istituto Maschile Umberto 1.

Latassa, F. (1788), Biblioteca nueva de los escritores aragoneses, I, Pamplona.

Moreno, F. (1977), Historia y Arte de Uncastillo, Madrid.

Morte García, C. (1984), «La Iglesia de San Andrés de Uncastillo (Zaragoza), edificio funerario del siglo XVI del obispo Pedro del Frago», Artigrama 1, 147-176.

Morte García, C. (1985), «El testamento y la colección del obispo don Pedro del Frago (c. 1500-1584)», Artigrama 2, 57-75.

NichiLO, M. de (1995), «L'oratoria nuziale umanistica tra retorica del matrimonio ed elogio cortigiano», Euphrosyne 23, pp. 123-139.

Pedraza García, M. J. (2011), El conocimiento organizado de un hombre de Trento. La biblioteca de Pedro del Frago, obispo de Huesca, en 1584, Zaragoza, Prensas Universitarias.

Pozuelo Calero, B. (2004), El licenciado Francisco Pacheco. El túmulo de la reina doña Ana de Austria, Alcañiz-Madrid, IEH-Ediciones del Laberinto-CSIC.

Russell Guillot, H. (2001), Letras y fe. Erasmo en la Valencia del Renacimiento, Valencia, Institució Alfons el Magnànim.

Serrano Cueto, A. (2006), «La precipitación de Ambrosio de Morales en la publicación del Epithalamium Philipi et Isabelis (1560) de Diego de Guevara: avatares de la epístola nuncupatoria», Calamus Renascens 7, 179-196.

Serrano Cueto, A. (2008), «El epitalamio latino (1560) de Diego de Guevara en honor de Felipe II e Isabel de Valois», Calamus Renascens 9, 245-292.

Serrano Cueto, A. (2009a), «La Querela pacis de Erasmo en el epitalamio de Diego de Guevara en honor de Felipe II e Isabel de Valois», en Arcos Pereira, T. - Fernández LóPEZ, J. - MoYA DEL BAÑo, F. (eds.), Pectora mulcet. Estudios de retórica y oratoria latinas, II, Logroño, pp. 1043-1055.

Serrano Cueto, A. (2009b), «El Epithalamium de Jerónimo Ramírez en honor de la boda (1570) de Felipe II y Ana de Austria», HumLov 58, 103-124.

SERrano Cueto, A. (2011), «Las lágrimas de la noua nupta en la tradición del epitalamio latino», Minerva, 24, 137-155.

Soldati, B. (1902), Ioannis Ioviani Pontani carmina, II, Florencia.

Tournoy-Thoen, G. (1977), «Le manuscrit 1010 de la Biblioteca de Cataluña», HumLov 26, $1-75$.

ZANKer, P. (2005), Augusto y el poder de las imágenes, Madrid, Alianza Editorial. 